\title{
Giving Credit Where It's Due - The Complicated Practice of Scientific Authorship
}

\author{
Seth C. Rasmussen \\ Department of Chemistry and Biochemistry, North Dakota State University, Fargo, ND 58108 USA \\ E-mail: seth.rasmussen@ndsu.edu
}

Anyone who has participated in modern scientific publishing has experienced the potentially complex issue of coauthors, both in terms of who merits to be included on a particular paper and in what order should they be listed. During the early years of serial scientific publications in the $17^{\text {th }}$ and $18^{\text {th }}$ centuries, ${ }^{1}$ nearly all papers consisted of just a single author. In contrast, the growing complexity of most present-day studies has required collaborative teams to accomplish the work needed to present a suitable report meriting publication. ${ }^{2}$ Some have attempted to tie this move to multiple-author papers with the introduction of large-scale government funding following World War II. ${ }^{3,4}$ While valid arguments can be made about the expansion of the scientific enterprise at this point in history, ${ }^{4}$ simply browsing the contents of prominent journals shows that papers with two or more authors predated this event and were somewhat common by the second decade of the $20^{\text {th }}$ century. Of course, one can now easily find papers with 10 or more coauthors, further complicating the ability to properly recognize each author's specific contribution. As such, it is not surprising that the history of science includes various cases of authors not receiving sufficient credit for their contributions, and it was recent research into one such controversial case ${ }^{5}$ that has led to the current discussion. Unfortunately, there exists no firm, uniform rules for determining authorship 6 and current practices can vary significantly, ${ }^{7}$ even to the point that the literature is now plagued with ethically questionable practices such as coercive authorship ${ }^{4,7}$ (senior officials requiring authorship on the work of subordinates without any contribution), gift/honorary authorship ${ }^{4,6,8}$ (the addition of authors that did not actually contribute to the work out of respect or friendship), or the opposite case where actual contributors are given no credit whatsoever (sometimes referred to as ghost authorship ${ }^{4}$ ). As such, the goal here is to present various best practices in terms of both determining valid authorship, as well as addressing the related issue of author order on a given publication.

For most researchers, the baseline requirement for authorship is that the researcher should have provided a real contribution to the reported work. Of course, this does not mean that all contributors should be authors and the sticking point is often determining what merits authorship over a simple acknowledgement. One of the earliest attempts to define scientific authorship has been quoted $a s^{2}$

...someone who has made significant contribution to the project through planning, conceptualization, or research design; providing, collecting, or recording data; analyzing or interpreting data; or writing and editing the manuscript.

The American Chemical Society (ACS) then introduced their own take on a definition in 1985 as a part of the society's Ethical Guidelines to Publication of Chemical Research. As outlined by the ACS: ${ }^{9}$

The co-authors of a paper should be all those persons who have made significant scientific contributions to the work reported and who share responsibility and accountability for the results. Other contributions should be indicated in a footnote or an "Acknowledgments" section.

This definition has been retained nearly unchanged in each of the society's revised ethical guidelines since.

Of the currently available best practices, the International Committee of Medical Journal Editors (ICM- 
JE) included much of the ACS definition, while also attempting to provide more specific parameters. As such, the ICMJE recommended that to merit authorship, researchers must meet all of the following conditions: ${ }^{10}$ i) Substantial contributions to the study's conception/ design, data acquisition, or analysis/interpretation; $i$ ) Drafting the manuscript or critical revision for intellectual content; iii) Approval of the final manuscript to be published; iv) Accountability for the accuracy/integrity of the work. Thus, per ICMJE guidelines, contributors that meet all four of these conditions should be authors, while those that meet three or less should only be given a suitable acknowledgement. Of course, while this provides a simple rubric for deciding authorship, the actual threshold for meeting points $i$ and $i i$ is still somewhat vague. For instance, what exactly qualifies as a substantial contribution? Such standards can vary from one discipline or research group to another. ${ }^{7}$ Furthermore, the ICMJE guidelines reinforce the very traditional definition of an author as one who contributed to the actual writing of the manuscript and does not always allow credit for less traditional types of contributions to the published study.

An alternate, and somewhat more detailed, approach is the Contributor Roles Taxonomy (CRediT) introduced in 2014 and now adopted by a number of

Table 1. Contributor Roles Taxonomy (CRediT).

\begin{tabular}{|c|c|}
\hline Role & Description \\
\hline Conceptualization & Formulation of research goals and aims \\
\hline Methodology & Development or design of methodology used \\
\hline Software & $\begin{array}{l}\text { Programming, implementation of computer } \\
\text { code, or testing of existing code }\end{array}$ \\
\hline Validation & $\begin{array}{l}\text { Verification of the replication/reproducibility } \\
\text { of results/experiments }\end{array}$ \\
\hline Formal analysis & Use of formal techniques to analyze study data \\
\hline Investigation & Performance of experiments or data collection \\
\hline Resources & Provision of materials, reagents, samples, etc. \\
\hline Data curation & $\begin{array}{l}\text { Management activities to annotate and } \\
\text { maintain data for research and later re-use }\end{array}$ \\
\hline $\begin{array}{l}\text { Writing - } \\
\text { original draft }\end{array}$ & $\begin{array}{l}\text { Preparation/presentation of the published } \\
\text { work, specifically writing the initial draft }\end{array}$ \\
\hline $\begin{array}{l}\text { Writing-review/ } \\
\text { editing }\end{array}$ & $\begin{array}{l}\text { Critical review, commentary, or revision } \\
\text { of the published work }\end{array}$ \\
\hline Visualization & Preparation of data presentation/visualization \\
\hline Supervision & Oversight and responsibility for the research \\
\hline $\begin{array}{l}\text { Project } \\
\text { administration }\end{array}$ & $\begin{array}{l}\text { Management and coordination of the research } \\
\text { activity and execution }\end{array}$ \\
\hline $\begin{array}{l}\text { Funding } \\
\text { acquisition }\end{array}$ & Acquisition of financial support for the project \\
\hline
\end{tabular}

scientific publishers. ${ }^{11}$ As outlined in Table 1, this consists of 14 various roles for potential contributions to a given publication, with each author assigned appropriate roles upon submission of the manuscript. While no guidelines are provided in terms of the extent of contribution expected of each author, this approach does provide a practical way to acknowledge the diversity of researchers' contributions to published papers, particularly in large teams, as well as the ability to clearly document how each author contributed to the work. Still, it does become easier to justify authorship over a simple acknowledgement when it is clear that a researcher has contributed via multiple different roles. Furthermore, this new taxonomy attempts to move away from the traditional author role to the broader, and more realistic, role of contributor (even if still commonly referred to as a paper author in practice). ${ }^{11,12}$ Even if publishers have not explicitly adopted CRediT, many journals are now requiring that each author's contribution be explicitly described in a dedicated section of the published paper, which effectively accomplishes the same overall goal. Overall, application of at least the spirit of these best practices should help avoid the ethically questionable practices referenced above.

Once decisions have been made concerning which contributors merit authorship, there is still the thorny issue of author order, particularly in publications with a significant number of authors. By far the most common practice is to list authors according to their relative contributions to the work. That is, the author with the greatest contribution is given first author status, with others ranked in descending order of contribution. The only exception to this is typically the placement of the principle investigator (PI), who is most commonly listed last and designated as the corresponding author. However, even the placement of the PI can vary and sometimes the PI can be given first author status, either as the result of providing the bulk of the contributions (as in review articles, etc.), as the result of discipline traditions or convention, or in an attempt to increase the paper's perceived exposure.

As the number of first author publications can play a critical role in job applications, extramural funding, etc., ${ }^{3,4}$ deciding who merits first author status can be a tricky and contentious process, particularly in cases where multiple authors have provided somewhat similar contributions to the work. As a potential solution to this issue, the practice of designating multiple first authors has started to become common, in which footnotes are used to specify that each author contributed equally to the work. ${ }^{13}$ Even here, however, the first of the two "equal" authors still tends to receive greater recognition, 
particularly where only a single author is used to refer to the work. Although less common, similar practice can also be applied to the last/corresponding author, for those studies that involve multiple PIs. In reality, however, most collaborations (at least informally) have one PI that takes the lead responsibilities on each paper, thus removing the need for multiple corresponding authors.

As a way to remove the issues of author order, some fields have adopted the practice of listing authors in alphabetical order. The problem here is that unless this is made explicitly clear to the reader, most will still assume authors are listed in terms of relative contribution, as this is the far more common practice. Another compromise is the practice of what is sometimes referred to as negotiated order. That is, to come to some consensus or mutual agreement between authors on the listed order. For example, in cases where two researchers have provided near equal contributions, it is likely that the people in question will both contribute to more than one publication from the same project. Therefore, the order of first and second author on one publication can then be reversed on the next publication, thus providing an avenue of giving balanced credit across the total scope of the project.

Needless to say, while this discussion has attempted to present best practices, none of these approaches are perfect and there are still plenty of opportunities of argument and contention. In the end, for everyone involved (students and advisors, alike), the best practice is to have open and transparent discussions about these issues and try to come to agreement about these decisions prior to drafting the manuscript for publication. In addition, if the author order needs to be modified due to changes in team composition or relative contributions of authors, make sure that all authors understand the reasoning behind the applied changes. In the end, open communication is the only way to limit unwanted disputes related to the authorship of a given publication.

\section{REFERENCES AND NOTES}

1. D. A. Kronick, A History of Scientific and Technical Periodicals. The Origins and Development of the Scientific and Technological Press 1665-1790. The Scarecrow Press, Inc., New York, 1962.

2. M. M. Jennings, I. H. El-adaway, J. Prof. Issues Eng. Educ. Pract. 2012, 138, 37-47.

3. D. S. Price, Science 1981, 212, 986.

4. K. Strange, Am. J. Physiol. Cell Physiol. 2008, 295, C567-C575.

5. S. C. Rasmussen, Substantia 2021, 5, 91-97.

Rasmussen, Substantia 2021, 5, 91-97.
6. V. Venkatraman, Science 2010, 10.1126/science. caredit.a1000039.

7. M. Hosseini, L. Consoli, H. A. E. Zwart, M. A. van den Hoven, Sci. Eng. Ethics 2020, 26, 597-617.

8. M. Biagioli, Trends in Chemistry 2019, 1, 3-5.

9. ACS Books and Journals Division, Environ. Sci. Technol. 1986, 20, 559-560.

10. Defining the Role of Authors and Contributors, ICMJE, http://www.icmje.org/recommendations/ browse/roles-and-responsibilities/defining-the-roleof-authors-and-contributors.html (accessed December 3, 2020).

11. L. Allen, A. O'Connell, V. Kiermer, Learned Publishing 2019, 32, 71-74

12. A. Holcombe, Nature 2019, 571, 147.

13. M. Hosseini, Sci. Eng. Ethics 2020, 26, 1133-1148. 